\title{
Alimentos internacionales
}

\author{
Alicia M. Perugini Zanetti
}

"A) Prof. Clóvis do Couto e Silva: porque cada persona se define por la opción que elige y su elección fue la verdad y la justicia."

A - Jurisdicción internacional y derecho aplicable a los alimentos entre cónyuges.

\section{I- Jurisdicción internacional}

1- Derecho convencional. Tratados de Derecho Civil Internacional de Montevideo de 1889 (TDCIM 1889) y de 1940 (TDCIM 1940).

1.1- Petición de alimentos en el contexto de un juicio de divorcio, separación o nulidad.

1.2-Alimentos entre cónyuges planteados fuera de un juicio de divorcio, separación o nulidad.

2 - Derecho de fuente interna.

2.1- Petición de alimentos en el contexto de un juicio de divorcio, separación o nulidad.

2.2- Alimentos entre cónyuges planteados fuera de un juicio de divorcio, separación o nulidad.

II - Derecho aplicable

1. Derecho convencional. Tratados de Montevideo de Derecho Civil Internacional de 1889 y 1940.

1.1- Derecho aplicable a los alimentos dentro del matrimonio.

1.2- Derecho aplicable a los alimentos entre ex-cónyuges.

2 - Derecho de origen interno. Código Civil. Derecho aplicable a los alimentos dentro y fuera de los matrimonios. 
3 - Uniones de hecho.

B - Jurisdicción internacional y derecho aplicable a los alimentos en materia de menores.

I - Jurisdicción internacional

1- Derecho convencional.

Tratados de Derecho Civil Internacional de Montevideo de 1889 y de 1940

2- Derecho de fuente interna.

II- Derecho aplicable a los alimentos de menores

1 - Derecho de fuente convencional

2- Derecho de fuente interna

C - Convención sobre obtención de alimentos en el extranjer ${ }^{1}$ (Convención de Nueva York, Ley 17.156; B.O. 10-II-67)

D. Convención Interamericana sobre obligaciones alimentarias.

\section{INTRODUCCIÓN}

No nos debe causar extrañeza - ya que se trata de una obligación de naturaleza asistencial - que uno de los problemas más sensibles en el derecho de familia, tanto en el orden interno como en el internacional, sea el de los alimentos.. Por esa razón, diferentes organismos internacionales como la organización de las Naciones Unidas (ONU), la Conferencia de La Haya y la Organización de los Estados Americanos (OEA), escogieron la cuestión alimentaria como materia de tratados.

Bueno es recordar que el derecho alimentario se reconoce en todos los países, tanto en los que prevalece el derecho privado como en los que predomina el derecho público, y comprende un vasto panorama que incluye el ámbito matrimonial, el paterno - filial y las relaciones de parentesco ${ }^{2}$. En algunas legislaciones se asimilan a los familiares, las personas impedidas que están en relación de dependencia y las uniones de hecho, por ejemplo 3 .

Nombre de la Convención modificada conforme al original por ley 19.739, B.O. 28-VIl-72.

2 Vaz Ferreira Eduardo y colaboradores, Obligación alimentaria familiar en América Latina, publicación de la Unidad de Asuntos Jurídicos del Instituto Interamericano del Niño, Montevideo, Uruguay, 1989.

${ }^{3}$ Ver de la autora: "Jurisdicción internacional alimentaria entre cónyuges" en La Ley del 12 de agosto de 1986. 
El problema de los alimentos puede ser enteramente nacional o bien derivada u originariamente internacional.

En el caso exclusivamente nacional la solución se la encuentra en las fuentes de origen interno. Todavía no se ha llegado a la elaboración de tratados comunes a varios estados con normas sustantivas sobre alimentos. En estos casos sólo readquiriría relevancia la jurisdicción internacional y el derecho aplicable en tanto haya interpretaciones concordantes o discordantes de los jueces de los diferentes países ${ }^{4}$.

El caso derivadamente internacional nace como nacional y en el decurso del tiempo se internacionaliza: tal el supuesto de los alimentos en un divorcio totalmente nacional, con cónyuges domiciliados, bienes y prestación a cumplirse en la Argentina. Hasta aquí la solución se determina conforme al derecho argentino elaborado para cuestiones nacionales. Si luego el deudor alimentario trasladara su domicilio a otro país, se plantearía el problema de la jurisdicción y el derecho aplicable. Estaríamos, entonces, ante la transformación del caso nacional en uno internacional y habría que partir del Derecho Internacional Privado argentino, de origen convencional o de origen interno.

En cambio, si en un comienzo, el aspirante a acreedor y el supuesto deudor se encontraren en estados diferentes, el caso sería originariamente internacional. Así, por ejemplo, cuando padre e hijo residen en forma permanente en diferentes países y se reclaman alimentos.

El problema alimentario internacional es más complejo que el nacional, pues a los problemas del derecho interno, se suman los provocados por la búsqueda de la jurisdicción internacional y los ocasionados por el funcionamiento de las normas de conflicto. Además, es menester recordar que es una institución vinculada, tanto si se la considera una obligación legal ${ }^{5}$ o una obligación dineraria ${ }^{6}$, como si se la vincula a un derecho causal, ordinariamente originado en alguna relación del derecho de familia, como el matrimonio, la filiación y las relaciones de parentesco. Estas circunstancias la pueden hacer dependiente - por lo menos en última instancia - de la validez de las situaciones o relaciones que originan la pretensión y la obligación alimentaria. Es necesario, entonces, delimitar el

\footnotetext{
${ }^{4}$ Es bueno recordar que la diferencia de interpretaciones no es patrimonio exclusivo de los casos internacionales

${ }^{5}$ Hay una obligación de los Estados de amparar a menores abandonados que se encuentran en su territorio, aunque "pertenezcan" a otros países, sea por residencia habitual, sea por nacionalidad. Por ejemplo, la Convención en análisis dispuso que "Los Estados Parte procurarán suministrar asistencia alimentaria provisional en la medida de sus posibilidades a los menores de otro Estado que se encuentren abandonados en su territorio"en el artículo 19 (Disposiciones Generales) - Ver en Opertti Badán, "Exposición de motivos del Proyecto de convención Interamericana sobre conflicto de Leyes en materia de alimentos para menores", en Instituto Interamericano dél Niño, OEA, Unidad de asuntos Jurídicos, páginas 1 y 2 y nota 1 un panorama de los distintos encuadramientos que se atribuyen al derecho alimentario. En el Derecho Internacional Privado, la cuestión pertenece al problema de las calificaciones.
} 
derecho aplicable a los alimentos, del derecho aplicable a las instituciones causales. Como se verá más adelante, en las convenciones internacionales, se ha independizado la cooperación alimentaria del derecho causal con el propósito de no entorpecer esa prestación sensible con problemas de fondo.

Cabe recordar también que, aunque en nuestro país la obligatoriedad de prestar alimentos es de orden público - por su propia naturaleza asistencial - las modalidades de la prestación, como monto, forma de pago y lugar de pago, pueden acordarse mediante convenios entre las partes. En estos casos cabría indagar si dichos convenios se rigen por otro derecho que el que regula a los alimentos y si primaría la autonomía de la voluntad sobre normas imperativas internas.

El derecho sustantivo, a su vez, abarca un amplio panorama de problemas, como por ejemplo, quiénes pueden ser acreedores; los que deben ser deudores; el quantum del monto; la relación entre éste y el nivel de vida del alimentante; las modalidades de pago, la relación entre la constitución del bien de familia y la institución alimentaria y otros problemas?

No menos importantes son los aspectos procesales, como por ejemplo, los concernientes a la jurisdicción internacional y a las cuestiones probatorias, vgr. la prueba directa o indiciaria que orienta al magistrado en la estimación del monto. Tảmbién conviene recordar que la resolución otorgando o denegando los alimentos tiene el efecto de cosa juzgada formal, circunstancia que hay que tener en cuenta al darle validez extraterritorial a la decisión.

Como en todo caso internacional, es menester distinguir entre las fuentes de origen convencional y las de origen interno. Entre las de origen convencional - aunque no traten específicamente el tema alimentario - encontramos los Tratados de Derecho Civil y Derecho Procesal de Montevideo de 1889 y de 1940. Entre las que regulan especialmente a la materia, hallamos la Convención sobre obtención de alimentos en el extranjero (Convención de Nueva York, Ley 17.156; B.O. 10-II-67), (en adelante Convención de Nueva York), y la Convención Interamericana de obligaciones alimentarias de Montevideo de 1989, todavía no aprobada ni ratificada por la Argentina $^{8}$ (en adelante Convención interamericana).

\footnotetext{
7 Para el estudio del tratamiento de los alimentos en el derecho argentino, ver Gustavo Bossert, Régimen Jurídico de los Alimentos, ASTREA,1993.

8 El 22-X-1997 se inició en el Ministerio de Justicia el trámite interno para gestionar la aprobación por parte del Poder Legislativo (Expte. № 115.637, con dictamen favorable de la Dirección de Derecho de la Integración). El Ministerio de Justicia lo remitió al Ministerio de Relaciones Exteriores, Comercio Internacional y Culto, haciéndole saber del interés de su aprobación. Con anterioridad la 2a. Reunión de Ministros de Justicia del Mercosur recomendó su estudio con miras a su ratificación (Acta № 1/92. Puerto Iguazú, Pcia. 20, 21, 22 de mayo de 1992. A la fecha no fue aprobada por la Argentina.
} 
En el ámbito interno contamos con el Código Civil (redacción de la ley 23.515) en lo concerniente a los alimentos entre cónyuges. Carecemos de normas específicas respecto de menores y parientes en materia de alimentos internacionales, por lo cual hay que acudir a la analogía.

Aunque los alimentos internacionales abarcan una gama muy variada de acreedores y deudores, como por ejemplo, cónyuges, ex cónyuges, uniones libres, menores, ascendientes y descendientes, colaterales, parientes y afines," este trabajo estará limitado a la jurisdicción internacional y a algunos aspectos del derecho aplicable a cónyuges, ex-cónyuges y menores.

\section{A - JURISDICCIÓN INTERNACIONAL Y DERECHO APLICABLE A LOS ALIMENTOS ENTRE CÓNYUGES.}

\section{I- Jurisdicción internacional.}

Hay que diferenciar el tratamiento que se brinda a los alimentos en las fuentes convencionales o de origen interno, según se soliciten en el contexto de un juicio de divorcio, separación o nulidad o se pidan como principal petición.

1- Derecho convencional. Tratados de Derecho Civil Internacional de Montevideo de 1889 (TDCIM 1889) y de 1940 (TDCIM 1940). nulidad.

1.1. Petición de alimentos en el contexto de un juicio de divorcio, separación o

Si los alimentos se plantearen en ese contexto, ambos Tratados disponen la jurisdicción del Estado del domicilio conyugal (art. 62 de TDCIM 1889) y art.56 de (TDCIM 1940). El Tratado de 1940 agrega que, si no se conociere el domicilio conyugal, se estará al del último domicilio conyugal (art.9).

La petición de alimentos aparece como estatuto no autónomo absorbido por la jurisdicción que atiende al problema fundacional (divorcio, separación, nulidad). El derecho del Estado que tiene jurisdicción sobre el problema "principal" resolverá, por ejemplo, del eventual trámite de los alimentos por la vía incidental. También, en principio, los tribunales del domicilio conyugal deberán decidir acerca de la legitimidad de la causa, las medidas urgentes y transitorias de subsistencia, las medidas permanentes, y la admisibilidad, oportunidad y alcance del convenio alimentario, si lo hubiere. La misma jurisdicción resuelve el contenido del caudal alimentario, su relación con los recursos del

\footnotetext{
${ }^{9}$ Vaz Ferreira Eduardo y colaboradores, "Obligación alimentaria familiar en América Latina", en publicación de la Unidad de Asuntos Juridicos del Instituto Interamericano del Niño, Montevideo, Uruguay, 1989
} 
alimentante y, en su caso, la adaptación por las fluctuaciones del tipo de cambio. nulidad.

\section{2- Alimentos entre cónyuges planteados fuera de un juicio de divorcio, separacióno}

Los Tratados no tienen normas especiales para resolver la jurisdicción internacional alimentaria entre cónyuges, cuando los alimentos se plantean como cuestión autónoma es decir - en el sentido de un tratamiento procesal relativamente desvinculado del juicio de divorcio o nulidad ${ }^{10}$. En el derecho de origen interno hablaríamos francamente de lagunas, lo cual se duda si de convenciones internacionales se trata.

Una solución sería aplicar las normas generales sobre jurisdicción de ambos Tratados (art. 56): la del Estado cuyo derecho rige el problema de que se trata y la del domicilio del demandado.

Esta respuesta acarrearía el inconveniente de tener que calificar "el problema de que se trata": ¿hay que encuadrarlo como efectos personales o como régimen de bienes?" . No tenemos tratados que resuelvan especialmente la cuestión de las calificaciones. Lamentablemente, la Convención Interamericana sobre Normas Generales de Derecho Internacional Privado no lo trata. Sin embargo, este inconveniente es superable: cuando se trata de cuestiones que hacen a la parte general det Derecho Internacional Privado, el impedimento de las lagunas no hace mella a la aparición de sus soluciones. En efecto, si estos "problemas" no son detectados por el legislador, el juez, en la cuestión sometida a

10 Hay quienes consideran a los alimentos como un derecho específico y autónomo. Opertti, I.c., pág. 2, nota 3) atribuye a Quintín Alfonsín el encuadre de los alimentos como derecho individual y autónomo en sentido amplio. Ver nota 11.

" En el ámbito interno la doctrina argentina mayoritariamente los ubica dentro de los efectos personales. Ver CNCiv., sala A, abril 8-1985.-B. de M. y C., Y. y otro contra M. y C. A. con comentario de Horacio Ferrer en El Derecho t. 114, pag. 97 y ss. En el Proyecto de Código Civil (Art. 2576) las relaciones personales entre los cónyuges son regidas por la ley del domicilio efectivo, entendiéndose por tal el lugar donde viven de consuno. En caso de duda o desconocimiento de éste, se aplica la ley de la última residencia. Empero, es de destacar que el Proyecto prevé una solución especial para los Alimentos entre Cónyuges. En efecto el Artículo 2577 establece: "El derecho de los cónyuges a percibir alimentos y la admisibilidad, oportunidad $y$ alcance del convenio alimentario, si lo hay, se rigen por la ley del domicilio conyugal. El monto de la obligación alimentaria se rige por el derecho del Estado del domicilio del acreedor o del deudor, el que a juicio de la autoridad competente, resulte más favorable al interés del acreedor". El Proyecto modificatorio del Anteproyecto de Código de DIPr. de Werner Goldschmidt, en lo atinente a las relaciones personales establece (Art. 44) que: "Los derechos y deberes de los cónyuges que no dependen del régimen de bienes establecidos entre ellos, se regirán por el derecho de su domicilio conyugal". También en este Proyecto hay normas especiales sobre alimentos: "El derecho a percibir alimentos y la admisibilidad y alcance del convenio alimentario se regirán por la ley del domicilio conyugal. El monto de la obligación alimentaria se regulará por el derecho del domicilio del demandado si tuere más favorable a la pretensión del acreedor alimentario. Las medidas urgentes se regirán por el derecho del país del juez que entiende en la causa. 
consideración, proyecta abierta o encubiertamente su solución ${ }^{12}$.

A título de ejemplo, si calificáramos a los alimentos como pertenecientes a los efectos personales, por el artículo 14 del Tratado de Derecho Civil Internacional de Montevideo de 1940, tendríamos que aplicar la ley del domicilio conyugal que es la que regula los derechos y deberes en el orden personal. En cambio, si los calificáramos como pertenecientes al régimen de bienes, según la misma obra de 1940, habría de aplicarse el artículo 16, que dispone que "las convenciones matrimoniales y las relaciones de los esposos con respecto a los bienes, se rigen por la ley del primer domicilio conyugal en todo lo que, sobre materia de estricto carácter real, no esté prohibido por la ley del lugar de la situación de los bienes". A nadie escapa la diferencia que podría haber en las respuestas a la cuestión alimentaria entre aplicar el derecho del domicilio conyugal actual (art. 14) o el derecho del primer domicilio conyugal (art. 16).

Otra solución - que parece la más acertada - dado el objeto y fin de los alimentos, es encuadrarlos como medidas urgentes, en cuyo caso la jurisdicción la tiene el estado en que residen los cónyuges. En efecto, por la teoría del paralelismo incorporada en los Tratados, el país cuyo derecho se aplica atrae consigo a la jurisdicción. El derecho rige los problemas urgentes, es el de la residencia de los cónyuges (art. 56 de ambos Tratados, artículo 24 del Tratado de 1889 y 30 del de 1940). Sin embargo, muchas veces, la residencia de pretendiente y demandado en diferentes estados - que generalmente aparecerá como presupuesto de la internacionalidad del caso - nos obligará a aplicar el de este último.

\section{2 - Derecho de fuente interna. Código Civil.}

La respuesta la hallamos en el Código Civil. En efecto, la ley 23.515 - incorporada al Código Civil - contiene una disposición especial sobre jurisdicción alimentaria internacional (art. 228, 1) y 2) que, en lo esencial, distingue el planteo de los alimentos dentro o fuera del juicio de divorcio, separación o nulidad del matrimonio.

\section{1- Petición de alimentos en el contexto de un juicio de divorcio, separación o nulidad.}

En este caso, tiene poder para resolver la cuestión el Estado que tiene la jurisdicción para entender en el juicio de separación, divorcio o nulidad del matrimonio, que es el del último domicilio conyugal efectivo o el del domicilio del demandado (art. 227, 1 y art. 228).

Ilustramos con un caso resuelto con anterioridad a la vigencia de la ley $23.515^{13}$.

\footnotetext{
$\sqrt{2}$ Goldschmidt, Derecho Internacional Privado, 8 edición, ed. Depalma, pags. 87 y ss.

${ }^{13}$ Caso: CNCiv., sala A, abril 8-1985.-B.de M. y C., Y. y otro C. M. y C. A (Con comentario de Horacio C. Ferrer en El Derecho, t. 114, pag 90 y ss.). El mismo caso, con comentario de la autora: "Jurisdicción internacional alimentaria entre cónyuges", en La Ley del 12 de agosto de 1986 (T. 1986-D-pag. 163).
} 
Se trata de un matrimonio celebrado en España entre una argentina y un español, del cual hubieron cuatro hijos - todos nacidos en España. La cónyuge, que reside en la Argentina junto a su hija menor, reclama alimentos del marido que continúa viviendo en España. Se trata de identificar las fuentes y las normas sobre la jurisdicción internacional alimentaria.

Según la decisión de la Cámara, como la petición de alimentos no se había presentado en un juicio de divorcio, no era aplicable el artículo 6 inc. 3ํ, del Código Procesal Civil y Comercial de la Nación. Regian, entonces, las reglas generales ${ }^{14}$ del art. 5ㅁ, inc 3 del citado Código. Según este texto tiene competencia el juez del lugar en que debe cumplirse la obligación y, subsidiariamente, a elección del actor, el del domicilio del demandado o el lugar del contrato, siempre que el demandado se encuentre en él, aunque sea accidentalmente al tiempo de la notificación. Quien no tuviere domicilio fijo podrá ser demandado en el lugar de la residencia.

El tribunal aplicó los arts. 24 y 30 de los Ts. de Derecho Civil Internacional de Montevideo de 1889 y de 1940, respectivamente, que hacen regir las medidas urgentes que conciemen a las relaciones personales entre cónyuges por el derecho de su residencia. El tribunal lo introdujo como principio general de derecho y no como recurso a la analogía. Concluyó que la conexión residencia debia agregarse a las soluciones jurisdiccionales mencionadas precedentemente.

2.2- Alimentos entre cónyuges planteados fuera de un juicio de divorcio, separacióno nulidad.

Cuando el problema de los alimentos se presenta como cuestión autónoma - por ejemplo, se introduce previamente a una demanda de divorcio o con posterioridad a la sentencia de divorcio - el Código ofrece diferentes alternativas de jurisdicción, a opción del actor: la del domicilio conyugal, la del domicilio del demandado, la de la residencia habitual del acreedor alimentario ${ }^{15}$, la del lugar del cumplimiento de la obligación alimentaria o la del lugar de celebración del convenio alimentario, si lo hubiere y coincidiere con la residencia del demandado, si se planteare como cuestión principal (art. 228,2).

Se puede interpretar que la jurisdicción del Estado en el que se dirime el juicio de separación, divorcio o nulidad de un matrimonio, es jurisdicción exclusiva para entender en los alimentos requeridos en ese contexto. No habría más opciones para el actor alimentario que las que la fuente ofrece para los problemas matrimoniales referidos. En cambio, las opciones que ofrece el artículo 228,2) del Código Civil pertenecen al actor que demanda alimentos en tanto se trata de una cuestión autónoma. Esta interpretación surge tanto de la aplicación analógica del art. 6, inc. 3², primera parte, del Código Procesal Civil y

\footnotetext{
${ }^{14}$ La aplicación de las reglas generales está prevista en el art. 6, inc,3, apartado 2.

${ }_{15}$ Puede entenderse por tal el del presunto acreedor. Ver, en ese sentido, Antonio Boggiano, Curso de Derecho Internacional Privado, De. Abeledo-Perrot pag. 388 y ss..
} 
Comercial de la Nación, como de las reglas del fuero de atracción y el principio de economía procesal.

La multiplicidad de posibilidades juega a favor tanto del aspirante a acreedor como del pretendido deudor, aunque generalmente la presentación de este último será, en la mayoría de los casos, una respuesta procesal a la pretensión del presunto acreedor.

Un problema no resuelto por la norma sobre jurisdicción alimentaria aparece cuando los sujetos de la reclamación alimentaria - confirmados en su relación por alguna resolución previa - solicitan, por ejemplo, que se modifique el monto o que cese la prestación.

El carácter tuitivo reclama que el demandante acreedor pueda acceder al mismo tribunal que le otorgó los alimentos, que generalmente coincidirá con el de su propio domicilio. Ello no obsta al hecho de que, si no hubiera reales contactos al tiempo de la petición con el Estado que otorgó los alimentos, se litigue en el del domicilio del demandante o en el del demandado. Este último asegura de entrada el reconocimiento de las sentencias y una rápida realización de la condena, por ejemplo. Cuando demandante y demandado están en diferentes países - que será en la mayoría de los casos internacionales - debería haber un buen sistema de cooperación jurisdiccional internacional para sostener la continuidad de la prestación alimentaria. En lo que a tratados se refiere, el MERCOSUR es bastante completo ${ }^{16}$.

Se presenta un problema acerca de la competencia de la autoridad qque entendió en la petición de alimentos para resolver en el cese y en la modificación. iEl grado de conexidad entre uno y otro problema o entre uno y otro proceso inciden en la jurisdicción internacional?. Estimo que no hay una respuesta precisa sino un principio preciso que debe informar - informar en sentido filosófico - la respuesta: es menester proteger al acreedor alimentario y de ahí identificar la jurisdicción más adecuada.

\section{II - Derecho aplicable.}

Identificada la jurisdicción internacional, la autoridad competente partirá de sus propias fuentes convencionales o internas para resolver el derecho aplicable a los alimentos.

1) - Derecho convencional. Tratados de Montevideo de Derecho Civil Internacional de 1889 y 1940.

1.1) Derecho aplicable a los alimentos dentro del matrimonio.

\footnotetext{
${ }^{16}$ Ver, por ejemplo, Protocolo de Cooperación y Asistencia Jurisdiccional en Materia Civil, Comercial, Laboral y Administrativa, Protocolo de Medidas Cautelares, Acuerdo sobre el Beneficio de Litigar sin Gastos y la Asistencia Jurídica Gratuita.
} 
Los Tratados de Montevideo no tienen normas típicas para regular los alimentos internacionales para cónyuges y ex cónyuges. Es menester resolver el problema encuadrándolo en las normas que se encuentren funcional y conceptualmente más próximas. Empero, para encontrarlas, primero hay que encuadrar - es decir, calificar el problema - .Como hemos dicho más arriba, los Tratados no resolvieron científicamente el problema de las calificaciones, es decir no lo regularon como problema general, más allá de algunas definiciones que irrumpen en el articulado.

La cuestión se vincula con el carácter no autónomo, en la mayoría de los casos, de la obligación alimentaria: existe en la medida que se le reconozca una causa y el encuadramiento se supeditará a la causa vinculada. Depende rá, por ejemplo, sỉ su origen se basa en relaciones matrimoniales, de filiación o de parentesco.

Tal como dijéramos más arriba, se los puede catalogar como pertenecientes a los efectos personales o al régimen de bienes. El tratamiento que se le brinde al problema de las calificaciones - teoría de la lex civilis fori, lex civilis causae, autárquica comparativa, autárquica valorativa, analógica - ecléctica, etc. - repercutirá en las soluciones.

Si lo calificáramos como perteneciente a los efectos personales, por el Tratado de Derecho Civil Internacional de Montevideo de 1889, habría que aplicar el derecho del domicilio conyugal (art. 12). Ante un cambio de domicilio, los derechos y deberes se rigen por el derecho del nuevo domicilio. En cambio, si lo encuadrásemos como perteneciente al régimen de bienes, se regirá por el derecho del país donde los cónyuges hubieran fijado el primer domicilio conyugal. Si no lo hubiesen fijado con anterioridad, el régimen de bienes se gobernará por el derecho del domicilio del contrayente al momento de contraer matrimonio. Si hubiere capitulaciones se regirán por lo que establecieren las capitulaciones (Arts. 40 a 43).

El Tratado de Derecho Civil de 1940 mantiene la solución dada por el de 1889 en lo concerniente a los efectos personales.(art.14). El régimen de bienes se rige por lo que establezcan las capitulaciones - si las hubiere. Caso contrario, por el derecho del primer domicilio conyugal (art, 16).

De especial interés es el artículo 30 de este Tratado que regula las medidas urgentes por el derecho del lugar donde residen los cónyuges ${ }^{17}$.

En ambos Tratados, como se advierte, el derecho aplicable afecta a la jurisdicción internacional (art. 56).

\footnotetext{
17 Las medidas urgentes también se extiende a los padres de familia, a los tutores y curadores y también se rige por el derecho de la residencia.
} 


\section{2-Derecho aplicable a los alimentos entre ex-cónyuges.}

Muchas veces la solicitud la plantean los ex cónyuges.

Los Tratados tampoco han previsto este problema. Puede aceptarse que rija, en principio, el mismo derecho que se aplicó a la cuestión dentro del matrimonio (ver 1.1.1), complementado - a elección de la autoridad judicial - por el derecho de la actual residencia del demandante o del demandado (art. 30).

2 -Derecho de fuente interna. Código Civil. Petición de alimentos planteados dentro y fuera de un juicio de divorcio, separación o nulidad.

El art. 162 del Código Civil califica a los alimentos como pertenecientes a los efectos personales y establece que "el derecho a percibir alimentos y la admisibilidad, oportunidad y alcance del convenio alimentario, si lo hubiere, se regirán por el derecho del domicilio conyugal. Por el mismo derecho se regirá el monto alimentario salvo que el derecho del domicilio del demandado fuere más favorable a la pretensión alimentaria".

La norma no distingue entre la petición de cónyuges y ex - cónyuges, así como tampoco si se plantean dentro o fuera de un juicio de alimentos. La elección del mejor derecho la tiene el juez. Ello no obsta a que el demandante colabore con el magistrado en la tarea de identificarlo.

Nos remitimos a lo expresado en el literal 2) respecto del derecho de fuente interna para ex cónyuges (Ver A, I, 2).

3) Uniones de hecho, No contamos con soluciones especiales para el ámbito internacional respecto de concubinos, convivientes, uniones libres o matrimonios no formalizados, cualquiera sea la denominación que se le dé, ni en las fuentes convencionales ni en las fuentes de origen interno. Empero, hay que recordar que en muchos países las uniones de hecho producen efectos jurídicos que van desde, por ejemplo, derechos sucesorios hasta derechos alimentarios, e inclusive - registración mediante - se los equipara al matrimonio formalizado ${ }^{18}$. Hay que aplicar analógicamente las normas referentes a los matrimonios.

\footnotetext{
${ }_{18}$ Ver Bossert, Gustavo, Régimen Jurídico del concubinato, Bs. As., editorial Astrea. Este autor dice que, si bien no hay obligación civil de darse alimentos entre concubinos pues no hay norma que lo dispone, puede tratarse de una obligación natural, con su secuela respecto a la no repetición de lo dado. El autor enumera alguna de las razones para admitirla como obligación natural. Por de pronto menciona al art. 515 que refiere a la equidad. Entre las consecuencias de esta obligación natural, además de la irrepetibilidad de lo pagado, se encuentra la validez de la fianza, hipoteca o prenda constituida por la concubina en garantía de la obligación de asistencia (arts.1993 y 518 CC interpretados extensivamente); se puede transformar la obligación natural en civil por novación; no se puede pedir la reducción de lo abonado; no se puede disponer la revocación de lo abonado por actos de ingratitud; no es necesario el cumplimiento de las formalidades exigidas para las donaciones. Si el concubina ha cumplido con algunas obligaciones no hay una obligación civil de cumplir con las restantes (ps.132 y ss.). Ver también Vaz Ferreira Eduardo y colaboradores, Obligación alimentaria familiar en América Latina, op.cit.
} 


\section{B - JURISDICCIÓN INTERNACIONAL Y DERECHO APLICABLE A LOS ALIMENTOS EN MATERIA DE MENORES.}

\section{I - Jurisdicción internacional}

1 - Derecho convencional. Tratados de Derecho Civil Internacional de Montevideo de 1889 y de 1940.2 - Convención sobre obtención de alimentos en el extranjero, (Convención de Nueva York , Ley 17.156; B.O. 10-II-67).

\section{1- Tratados de Derecho Civil Internacional de Montevideo de 1889 y de 1940}

La cuestión alimentaria de los menores no es contemplada como problema especial por los Tratados de Montevideo. Como los alimentos tienen como causa fuente la filiación o la patria potestad, parece razonable acudir a la jurisdicción prevista para éstas.

El Tratado de Derecho Civil Internacional de 1889 no contiene una norma específica para regular la jurisdicción en materia de filiación. Empero, podemos contar con la norma general del artículo 56 que nos envía al derecho del Estado por cuyo derecho se rige el problema de que se trata y el del domicilio del demandado. Remitiéndonos al derecho aplicable para identificar la jurisdicción internacional tendríamos que la filiación matrimonial, se rige por el derecho que rige la validez del matrimonio que es el del lugar de la celebración (arts. 16 y 11). La legitimidad de la filiación se rige por la ley del domicilio conyugal vigente al momento del nacimiento del hijo (art. 17). Por último, los derechos y deberes de la filiación ilegítima se rigen por el derecho del Estado donde han de hacerse efectivos (art.18). La jurisdicción inte rnacional, entonces, se encuentra en el lugar de la celebración (art. 11), en el domicilio conyugal vigente al momento del nacimiento del hijo (art. 17) y donde han de hacerse efectivos los derechos y deberes (art.18), según el problema de que se trate ${ }^{19}$.

Demás está decir que la aplicación irrestricta de la teoría del paralelismo podría acarrear situaciones poco prácticas e injustas, como, por ejemplo, la conexión procesal del lugar de celebración del matrimonio como conexión para resolver una cuestión de

\footnotetext{
${ }^{19}$ Ahora bien, por una parte, las fuentes que mencionamos distinguen entre filiación legítima e ilegítima, matrimonial y extramatrimonial y la legitimación por posterior matrimonio, entre otros temas. Por otra parte, la República Argentina, ha ratificado la Convención sobre los Derechos del Niño que descree de toda discriminación. Es indudable la repercusión de la Convención en las fuentes del Derecho Internacional Privado argentino - convencional e interno. En el mismo sentido la Convención Americana de Derechos Humanos (Pacto San José de Costa Rica). Cabe recordar que estos acuerdos tienen jerarquía constitucional. Se aplican sin más - derogando todo lo que se opone - o se aplica en la medida que beneficia al menor: "interés superior del menor". Con estas consideraciones previas se expone el tratamiento del derecho positivo argentino. Vanossi, Jorge Reynaldo A. y Dalla Vía, Alberto Ricardo, "Régimen Constitucional del los Tratados", Abeledo Perrot, segunda Edición, 2000, pág. y siguientes.
} 
alimentos, si no estuviere el domicilio del demandado o no hubiere bienes. Claro está, que el demandante hará méritos de la practicidad de elegir esa conexión.

El Tratado de Derecho Civil Internacional de Montevideo de 1889 dispone que la jurisdicción en lo concerniente a la patria potestad la tiene el país del domicilio de los padres (art. 59).

Por lo demás, el Tratado de Derecho Civil Internacional de Montevideo de 1940 reproduce en los artículos 20 y 21 las soluciones sobre filiación y legitimación del Tratado de 1889 y también sus normas sobre filiación extramatrimonial.

A diferencia del de 1889, el Tratado de Derecho Civil Internacional de Montevideo de 1940 no trata la jurisdicción internacional en materia de patria potestad. Una interpretación que podría darse es que - como el Congreso de 1939/40 se reunió para reformar el de 1889 - en todo aquello que no haya sido modificado y en cuanto sea compatible, regiría el de 1889. De no aceptarse esta interpretación se aplicará, entonces, la regla general contenida en el art. 56, que como vimos, nos envía al derecho del Estado por cuyo derecho se rige el problema de que se trata y el del domicilio del demandado. Tiene el agregado de admitir la prórroga de jurisdicción post litem en cuestiones personales patrimoniales.

El derecho aplicable a la patria potestad en lo concerniente a las relaciones personales y al régimen de bienes es el del domicilio de quien la ejercita (arts. 18 y 19). Ambos tipos de problemas comparten el mismo punto de conexión. Pareciera que, al contar dos problemas diferentes con un mismo punto de conexión para identificar el derecho aplicable, estamos eximidos de utilizar el complejo procedimiento de las calificaciones. En efecto, identificado el estado del domicilio de quien la ejercita, habrá de acudirse a las normas de un solo país que regulan los alimentos cualquiera sea su encuadre, es decir, como pertenecientes a las relaciones personales o al régimen de bienes. En definitiva, habrá un problema de encuadramiento del problema en la norma cuyo tipo legal se adecue al caso o - a la inversa - la subsunción del caso en el tipo legal de la norma que lo describa. En todo caso hay que calificar el punto de conexión.

En ambos Tratados la jurisdicción para medidas urgentes la tienen los jueces del lugar de residencia de las personas (artículo 64 y 20, Tratado de Derecho Civil Internacional de Montevideo de 1889 y artículos 61 y 30 del Tratado de Derecho Civil Internacional de Montevideo de 1940). Goldschmidt entiende que hay que interpretar que no sólo se trata de la residencia de los padres, sino también la de la persona sobre la que recae la medida urgente ${ }^{20}$.

20 Ver Werner GOLDSCHMIDT: "La recuperación por la madre de un hijo secuestrado por el padre" (El Derecho, T. 67, pág. 45). 


\section{Derecho de fuente interna.}

No encontramos normas sobre la materia. Se aplican analógicamente los Tratados de Montevideo.

\section{II- Derecho aplicable a los alimentos de menores}

1- Derecho de fuente convencional. Tratados de Montevideo de Derecho Civil Internacional de 1889 y de 1940.

Los Tratados de Montevideo carecen de normas especiales sobre derecho aplicable a los alimentos para menores. En cambio, regulan los efectos personales y el régimen de bienes de la patria potestad. También para el derecho aplicable se presenta el problema de su calificación como efectos personales o régimen de bienes.

El Tratado de Derecho Civil Internacional de 1889 establece que los efectos personales se rigen por el derecho del lugar en que se ejecutan (art. 14). No aclara si por realización de la ejecución se entiende el país de donde parten las decisiones, por ejemplo el del domicilio del o de los titulares de la patria potestad en un país, o adonde llegan las decisiones, vgr. la residencia del hijo en otro. El régimen de bienes se rige por el derecho del lugar de la situación (Art. 15). Al igual que en el matrimonio, el encuadramiento en uno u otro efecto dependerá de las calificaciones.

El problema de las calificaciones no se presenta en el Tratado de Derecho Civil Internacional de Montevideo de 1940 pues tanto los efectos personales como el régimen de bienes se rigen por el derecho del domicilio del titular de la patria potestad. Como se dijera más arriba, en todo caso hay que calificar el punto de conexión.

\section{Derecho de fuente interna}

El DIPr. de origen interno no resuelve estos problemas en la esfera internacional. Es menester aplicar analógicamente cl Tratado de Montevideo de 1940 en lo concerniente a la jurisdicción internacional y al derecho aplicable. Una vez que se ratifique la Convención Interamericana sobre obligaciones alimentarias sería ésta la normativa más próxima al problema alimentario, si es que para entonces no hay una regulación específica de origen interno.

Como se advierte, aparece nuevamente el problema de las calificaciones, aunque bueno es ir adelantando que hoy casi no se discute en la región a la que pertenecen los Tratados, el carácter de efectos personales. 


\section{C - CONVENCIÓN SOBRE OBTENCIÓN DE ALIMENTOS EN EL EXTRANJERO (CONVENCIÓN DE NUEVA YORK, LEY 17.156; B.O. 10-II-67)}

Esta Convención, elaborada en el marco de las Naciones Unidas, facilita la cooperación entre los Estados Partes en la circulabilidad internacional de los instrumentos de constancia de los derechos alimentarios. Para ello regula la actividad de órganos estatales de los estados del demandante - lo denomina "autoridad remitente" - y del demandado - identificada co mo "autoridad intermediaria" - sin resolver sobre la jurisdicción internacional, el derecho aplicable y el reconocimiento de sentencias ${ }^{21}$.

La internacionalidad del caso se produce cuando demandante y demandado se encuentran en diversas Partes Contratantes ${ }^{22}$. El concepto "se encuentra" - poco técnico - seguramente refiere a la residencia ( art. 1ㅇ, 1). Por su parte el art. 3, 1, reafirma esta conexión cuando dispone que el demandante podrá presentar la solicitud de alimentos ante la Autoridad Remitente del Estado donde "se encuentra" (art.3, 1) para que la transmita a la Institución Intermediaria del Estado del demandado ${ }^{23}$.

Para facilitar la circulación de los instrumentos se establece un sistema centralizado: Autoridades Remitentes (judiciales o administrativas) e Instituciones Intermediarias (públicas o privadas). La Convención es amplia y abarca todo tipo de causal alimentaria.

La solicitud debe ir acompañada de la identificación y domicilio del demandado, actos judiciales del tribunal competente de cualquiera de las partes contratantes y otros requisitos enumerados en los artículos 3 , ap. 4 y 5 .

La Convención no resuelve el problema de la Jurisdicción internacional ${ }^{24}$ para entender en un juicio de alimentos, mas bien se ocupa de facilitar la cooperación entre autoridades de diferentes Estados a fin de allanar la obtención de alimentos.

En cambio, prevé que la ley aplicable a la resolución de las acciones de alimentos y de toda cuestión que surja con ocasión de las mismas, será la ley del Estado del demandante, inclusive el derecho internacional privado de ese Estado. No aparece demasiado claro si por ley aplicable a la "resolución de las acciones" se entiende una cuestión procesal - inclusive jurisdiccional - o si refiere a la prestación de alimentos. Me

\footnotetext{
${ }^{21}$ Ver Opertti Badán, Exposición de motivos del Proyecto de Convención Interamericana sobre conflicto de Leyes en materia de alimentos para menores, en Instituto Interamericano del Niño, OEA, Unidad de asuntos Jurídicos, nota explicativa de esta última en página v.

${ }_{22}$ Hay que interpretar como tal a los Estados ratificantes.

${ }^{23}$ Es decir, donde "se encuentra" el demandado.

${ }^{24} \mathrm{La}$ falta de solución a este problema ha merecido acertadas críticas por parte de Horacio $\mathrm{C}$. Ferrer (Ver nota 13),
} 
inclino por esta última interpretación. El ámbito procesal no está comprendido - según algunas concepciones - en el contenido del DIPr. mientras que, en otras lo abarca. Tampoco es claro qué debe entenderse por ley del estado del demandante. Dado que es una Convención de las Naciones Unidas, ratificada por Estados que acogen a la conexión nacionalidad y estados que acogen al domicilio o a la residencia, seguramente su precisión surgirá de la "lex fori".

Los elementos de prueba se rigen por el derecho del estado de la Institución Intermediaria del demandante. Cabe interpretar que hace referencia a los tipos de prueba, como por ejemplo prueba testimonial, documental, etc.

El control del cumplimiento de los requisitos exigidos por la ley de la Institución Intermediaria lo realiza la Autoridad Remitente, la que también transmite la documentación (arts. 4 y 5 ).

La Convención regula dos modalidades: la circulación internacional de una resolución reconociendo alimentos procedentes de un estado para surtir efectos en otro, que se puede tramitar vía exhortos (art. 7), y la posibilidad de que el demandante otorgue poder a la Institución Intermediaria para que actúe en su nombre en un juicio de alimentos o designe a un tercero con ese objeto en el país del demandado.

\section{D - CONVENCIÓN INTERAMERICANA SOBRE OBLIGACIONES ALIMENTARLAS}

Esta Convención fue elaborada en el marco de la Organización de Estados Americanos (OEA) en la cuarta Conferencia Especializada sobre Derecho Internacional Privado (CIDIP IV), en Montevideo (Uruguay), del 9 al 15 de Julio de 1989. Son países signatarios: Bolivia, Brasil, Colombia, Costa Rica, Ecuador, Guatemala, Haití, México, Panamá, Paraguay, Perú, Uruguay y Venezuela. La ratificaron Belice, Bolivia, Brasil, Costa Rica, Ecuador, Guatemala, México, Panamá, Paraguay y Uruguay. Como se advierte, la han ratificado los Estados Partes del MERCOSUR, menos la Argentina, y Bolivia, Estado Asociado del MERCOSUR.

La Convención Interamericana trata la jurisdicción, el derecho aplicable y la cooperación procesal internacional referente a obligaciones alimentarias respecto de menores y a las que se deriven de las relaciones matrimoniales entre cónyuges o quienes lo hayan sido. Los Convenios elaborados en el marco de la OEA tienen un tiempo de preparación relativamente escaso ${ }^{25}$ y por esa razón no quiso ampliarse el ámbito de

\footnotetext{
${ }^{25}$ Por ello se reconoce una vital importancia a las reuniones preparatorias, como en el caso de esta Convención Interamericana sobre Alimentos la que se realizó en San José de Costa Rica con anterioridad a la Conferencia Interamericana de Derecho Internacional Privado de Julio de 1989. - El Grupo de Expertos trabajó con base a un Proyecto presentado por la delegación del Uruguay, de autoría del Prof. Dr. Didier Opertti Badán.
} 
aplicación material a otros vínculos. La Convención Interamericana deja la puerta abierta para incluir otras relaciones, como, por ejemplo, ascendientes y descendientes, al establecer que los Estados tienen posibilidad de ampliarla a favor de otros acreedores (art. 3). Así como puede ampliarse su ámbito de aplicación, los Estados también pueden limitarla a los menores (art.1, último apartado).

La libertad que tienen los Estados para delimitar el ámbito de aplicación material de la Convención plantea algunos interrogantes. Supongamos dos Estados ratificantes, uno ha ampliado su ámbito de aplicación a ascendientes y descendientes y el otro lo ha limitado a los menores. Ahora bien, se presente en este último una sentencia condenatoria de un cónyuge o de un hijo a pagar alimentos a favor del otro cónyuge o del padre. ¿Puede negarse el Estado requerido argumentando que limitó el ámbito de aplicación a los menores?. ¿O el ámbito de aplicación constituye un imperativo a los propios jueces para arrogarse la competencia sólo dentro de los límites que le fija el ámbito?. Por la redacción de los artículos 3, 4 y 21 parece suficiente que basta que en un país ratificante haya un derecho a percibirlo, para que los demás tengan que respetarlo, aunque la causal no se reconozca en su propia legislación, lo cual es coherente con el carácter asistencial de los alimentos.

Con respecto a los menores, define como tales a quienes no hayan cumplido 18 $a_{n} s^{26}$. La discrepancia con respecto a la edad entre lo que establece el derecho sustantivo argentino (Código Civil) y la exigida en la Convención, en principio, debería resolverse a favor de esta última, a tenor de la jerarquía que marca el art. 75, inc. 22 de la Constitución Nacional. Sin embargo, desde el punto de vista alimentario puede ser más benefícioso para el menor que se lo considere tal y no que se lo estime mayor. En síntesis, cabe interrogarse si el principio fundante de la Convención de la ONU incorporada a la Constitución Argentina, tiene como tal, mayor jerarquía que la Convención Interamericana. Habría que meditar en torno al interés superior del menor - principio fundante de la Convención de los Derechos del Niño (ONU) - que es uno de los Tratados de jerarquía constitucional. En cambio, la Convención Interamericana tiene origen internacional pero carece de jerarquía constitucional.

La minoridad es un requisito para dinamizar la obligación de los que tienen un vínculo con el menor. Es un dato necesario, pero no suficiente. Hay que identificar, por de pronto, al deudor alimentario, su vinculación con el acreedor y la causa que genera la obligación. La Convención no da respuestas específicas al derecho aplicable a los vínculos familiares y de parentesco. Por ejemplo, no regula ningún tipo de filiación y no dispone sobre el derecho que regula la validez del matrimonio o los títulos en que se fundan otras

${ }^{26}$ El Proyecto de Opertti resolvía el problema con una norma indirecta que remitía al derecho del país de la residencia habitual. Ver Opertti Badán, Exposición de motivos del Proyecto de Convención Interamericana sobre conflicto de Leyes en materia de alimentos para menores, I.c. págs. 9 y ss. 
pretensiones. Por ello, una decisión que concede alimentos no prejuzga, en última instancia, sobre la legitimidad de percibirlos (art. 5). La idea que inspiró el tratamiento autónomoen cierta medida - de la relación alimentaria es la de preservar el carácter tuitivo de los alimentos de la discusión del fondo de la cuestión. Es decir que el carácter de hijo o de esposa, por ejemplo - no dilate su obtención. ${ }^{27}$

Ahora bien, aunque la Convención no regula la institución en la que se funda la obligación alimentaria, con criterio realista, ha brindado una solución: establece que la calidad de acreedor y de deudor alimentario - y por ende, la obligación de dar y el derecho a recibir alimentos - se rige por el derecho del domicilio o residencia habitual del acreedor o del deudor ${ }^{28}$

No es seguro si esta remisión recae en el derecho interno o en el derecho internacional privado de uno u otro estado. En este último caso estaríamos ante el problema general del reenvío ${ }^{29}$. Como en todo caso habrá que estar al derecho más beneficioso al acreedor alimentario - sin entrar en polémicas sobre la aceptación o rechazo del reenvío - cuantos más derechos entren en la visión del juez, más posibilidades de beneficiar al menor (art. 6). Entre los derechos a tener en consideración se encuentra el del foro (art.21).

La Convención dejó al Juez el cometido de la elección, aunque la delegación Argentina estimó que hubiera sido preferible que la decisión recayera en el acreedor como ocurre con la elección de la jurisdicción - pues nadie mejor que el propio acreedor para conocer sus intereses. La decisión por parte de la autoridad judicial no empece al acreedor alimentario a suministrarle un menú de posibilidades.

El artículo 7 dispone los aspectos regidos por el derecho aplicable: el monto del crédito alimentario y los plazos y condiciones para hacerlo efectivo; la determinación de quienes pueden ejercer la acción alimentaria en favor del acreedor, y las demás condiciones requeridas para el ejercicio del derecho de alimentos. Por su parte, el Artículo 10 preceptúa

\footnotetext{
27 Ver Opertil Badán, Exposición de motivos del Proyecto de Convención Interamericana sobre conflicto de Leyes en materia de alimentos para menores, I.c.. Ver especialmente páginas 10 a 12.

${ }^{28}$ En la Convención de La Haya de 1973, la regla general es la aplicación del derecho de la residencia habitual del acreedor alimentario (art.4), y en caso de que no pueda obtener alimentos en virtud de esta ley, se aplicará el derecho nacional común (art.5). En defecto de éstas, se aplica el derecho interno del juez (art.6). El derecho aplicable según la Convención sólo puede ser rechazado si es manifiestamente incompatible con el orden público. y aun cuando el derecho aplicable disponga otra cosa, se deben tener en cuenta las necesidades del acreedor y los recursos del deudor en cuanto a la determinación del monto de la prestación alimentaria (art.11).

29 Puede verse Soto, Alfredo Mario, "Derecho Internacional Privado: la importacón del derecho extranjero", Bs.As.-Madrid, Cludad Argentina-USAL, 2001.
} 
acerca de la medida de los alimentos, los cuales tienen que guardar proporción entre la necesidad del alimentario y la capacidad económica del alimentante.

La Convención establece jurisdicciones concurrentes a opción del acreedor alimentario, en tre el Estado del domicilio o de la residencia habitual del acreedor o del deudor y el Estado con el cual el deudor tiene vínculos personales más estrechos, tales como bienes, percepción de ingresos u obtención de beneficios económicos. Las conexiones procesales sirven tanto para identificar la jurisdicción (jurisdicción directa) como para responder al requisito de la jurisdicción del juez de la sentencia (jurisdicción indirecta).

Por último, la Convención admite cualquier jurisdicción con tal que el demandado en el juicio hubiera comparecido sin objetar la competencia. Para este último apartado se descarta el juicio en rebeldía (art. 8).

Aunque pareciera que el precepto incluye vínculos personales y reales - en este último cașo debido a la mención a los bienes - su categoriza ción de personal y la referencia a la posesión de bienes se debió a la dificultad de una delegación de admitir vínculos reales. $^{30}$

Las mismas autoridades son competentes para conocer de las acciones de cese y reducción de alimentos (art. 9). Este artículo pretende beneficiar al acreedor alimentario y evita que el deudor escoja a su interés una jurisdicción. Por otra parte será más fácil resolver la cuestión a la autoridad que los otorgó pues tendrá los antecedentes a mano. Empero estas conexiones procesales podrían acarrear dificultades si el acreedor alimentario hubiere litigado en su propio domicilio y lo hubiere mudado cuando quisiere ejercer el derecho a oposición ante una solicitud de reducción o cese. Una posición tuitiva sería, por ejemplo, otorgarle jurisdicción para estos casos al estado del nuevo domicilio del acreedor:

De crucial importancia es la cooperación procesal internacional regulada en los artículos 11, 12 y 13. Los contenidos de los preceptos no difieren sustancialmente de los que regulan y exigen otras fuentes vigentes en lo concerniente a la jurisdicción internacional, legalización, traducción, notificación aceptable para el Estado del reconocimiento de la sentencia, salvaguarda de la defensa de las partes. Habida cuenta que una resolución sobre alimentos no produce el efecto de cosa juzgada material, el literal g) del artículo 11, requiere solamente su firmeza - y no el carácter de cosa juzgada - en el Estado en que fue dictada. En el mismo orden de id eas el artículo 17 dispone que, en materia de alimentos, las resoluciones interlocutorias y las medidas provisionales se trate o no de un proceso serán ejecutadas por la autoridad competente aun cuando estuvieran sujetas a recursos de apelación en el Estado donde fueron dictadas. El carácter

${ }^{30}$ Así lo explicó el delegado de los Estados Unidos - Frederich Juenger - en la reunión del grupo de Expertos en San José de Costa Rica. 
tuitivo se manifiesta también pues la convención establece que, en caso que existiere apelación de la sentencia, ésta no tendrá efecto suspensivo.

El Artículo 12 dispone sobre la documentación que debe acompañarse a la solicitud de reconocimiento. El control de los requisitos y de los documentos exigidos por los artículos 11 y 12 corresponderá directamente al juez, quien actuará en forma sumaria, con audiencia de la parte obligada, mediante citación personal y con vista al Ministerio Público, sin entrar en la revisión del fondo del asunto. Aún en el caso de que la resolución fuere apelable, el recurso no suspenderá las medidas provisionales ni el cobro y ejecución que estuvieren en vigor (Art. 13).

Se exime de caución al acreedor por ser extranjero o tener domicilio o residencia en el extranjero y se reconoce extraterritorialmente el beneficio de pobreza declarado en un Estado Parte (Art. 14.) ${ }^{31}$.

La Convención regla el otorgamiento por parte de las autoridades jurisdiccionales, de medidas provisionales o de urgencia de carácter territorial. La solicitud puede presentarla la parte interesada o el agente diplomático o consular. La concesión de la medida es independiente del Estado que tenga la jurisdicción internacional. En todo caso, para su otorgamiento basta que en el territorio haya bienes o ingresos (Artículo 15). El Artículo 19 trata también de medidas provisionales, pero adoptada por los Estados sin necesidad de requerimiento. El precepto dispone que "Los Estados se comprometen en la medida de sus posibilidades a suministrar asistencia alimentaria provisional a menores de otro Estado que se encuentren abandonados en su territorio. En la misma línea el artículo 16 dispone que el otorgamiento de medidas provisionales o cautelares por parte de un Estado no lo compromete para reconocer posteriormente la sentencia.

Entre las obligaciones de los Estados Parte se encuentra la de facilitar la transferencia de fondos en cumplimiento de las resoluciones que se dictaren por aplicación de la Convención (Artículo 20).

La aplicación del derecho extranjero y la ejecución de sentencias extranjeras podrán ser denegadas si conculcare manifiestamente los principios fundamentales de su orden público (art. 22).

\footnotetext{
${ }^{31}$ Las soluciones del artículo 14 de la Convención en análisis sirvieron de fuente para el "Acuerdo sobre el beneficio de litigar sin gastos y la asistencia jurídica gratuita" elaborado en el marco de la Reunión de Ministros de Justicia del MERCOSUR y los Estados Asociados, Bolivia y Chile (aprobado por el Consejo del Mercado Común del MERCOSUR en la XIX Reunión celebrada en Florianópolis los días 14 y 15 de diciembre de 2000, Decisiones 49/00 y 50/00). El artículo 7 establece que "El beneficio de litigar sin gastos concedido al acreedor alimentario en el Estado Parte donde hubiere presentado su reclamación, será reconocido en el Estado Parte donde se hiciere efectivo el reconocimiento o la ejecución". Asimismo el artículo 9 prescribe "Los Estados Parte se comprometen a prestar asistencia juridica gratuita a las personas que gocen del beneficio de litigar sin gastos, en igualdad de condiciones con sus nacionales o ciudadanos".
} 


\section{CONCLUSIÓN}

Como se advierte, el Derecho Internacional Privado y el Derecho Internacional Procesal argentino de fuente convencional vigente no contienen un estatuto acabado para regular los alimentos. El recurso a la analogía por sí mismo no convence sobre todo si se lo compara con un texto específico como la Convención Interamericana sobre alimentos (CIDIP VI) que resuclve un variado menú de problemas con la sensibilidad que la materia requiere. La creatividad de los jueces - loable en cuanto a búsqueda de soluciones equitativas, como el caso expuesto en (A - I-2 - 2.1) - no es suficiente pues en el llamado "civil law", las soluciones generales las elabora el legislador.

De ahí la importancia de que la República Argentina ratifique la Convención sobre Alimentos elaborada en el ámbito de la IV Conferencia Internacional Interamericana de Derecho Internacional Privado (CIDIP IV). Refuerza la propuesta el hecho de que sea el único Estado Parte del MERCOSUR que no la ha ratificado y el aumento de casos en la sub región que requieren una solución unívoca. 